\title{
Anger, Emotional Expressivity and Psychological Well-Being in Sports Players
}

\author{
Nandini Sanyal $^{1 *}$, Tina Fernandes ${ }^{2}$, Nimra Vizarath ${ }^{3}$
}

\section{ABSTRACT}

The objective of the present study is to observe whether there is a difference between boys and girls engaged in Instrumental Aggression Sports and those engaged in Hostile Aggression Sports with respect to anger, emotional expressivity and psychological well-being and to observe whether there is a relationship between these variables. A non-probability purposive sampling method was used to select a sample of 160 sports players, among whom 80 (40 boys and 40 girls) were engaged in instrumental aggression sports and 80 (40 boys and 40 girls) were engaged in hostile aggression sports. The Multidimensional Anger Inventory (Siegel, 1986), Berkeley Expressivity Questionnaire (Gross, \& John, 1998) and Psychological Well Being Scale (Ryff\& Keyes, 1995) were administered to the participants. The results showed significant gender differences with respect to the dimension of anger arousal $(p<0.05)$. However, no significant differences were found between the sport players engaged in instrumental aggression and those engaged in hostile aggression with respect to anger, emotional expressivity, and psychological well-being. The results also reveal that anger was positively correlated with emotional expressivity and negatively correlated with psychological well-being in both the groups $(\mathrm{p}<0.05)$. Additionally, emotional expressivity was negatively correlated with psychological well-being in sports players engaged in instrumental aggression sports and hostile aggression sports $(\mathrm{p}<0.05)$. The present study brings to light the toxic effects of anger and how we can learn to process emotions to augment effective functioning and psychological well-being.

Keywords: Instrumental, Hostile, Anger, Emotional Expressivity, Psychological Well-Being.

In sports, aggression has been defined in two categories: hostile aggression and instrumental aggression. A hostile aggression sports' core aim intends harm or injure the opponent, and an instrumental aggression sport is that kind that utilizes the emotion of aggression to score a

\footnotetext{
${ }^{1}$ Asst. Prof., Dept. of Psychology, St. Francis College for Women, Begumpet, Hyderabad, India

${ }^{2}$ Head, Dept. of Psychology, St. Francis College for Women, Begumpet, Hyderabad, India

${ }^{3}$ Graduate Student, St. Francis College for Women, Begumpet, Hyderabad, India

*Responding Author

(C) 2016, N Sanyal, T Fernandes, N Vizarath; licensee IJIP. This is an Open Access Research distributed under the terms of the Creative Commons Attribution License (http://creativecommons.org/licenses/by/2.0), which permits unrestricted use, distribution, and reproduction in any Medium, provided the original work is properly cited.
} 


\section{Anger, Emotional Expressivity and Psychological Well-Being in Sports Players}

particular goal (Silva, 1983). Hostile aggression sport players intend to harm the opponent, and hostile aggression sports are the kind of sports where the goal itself is to harm and they, thus, require unusual effort and energy expenditure. Whereas, instrumental aggression sport players do not intend to harm the opponent, and in these sports the goal is to win and the aggression is directed solely towards that very intention (Silva, 1980).

A study was found that experienced sport players used more instrumental aggression that they utilized to their advantage, hostile aggression on the other hand was less frequently used. Experienced sport players used techniques of self-control to help themselves with aggression (Coulomb \& Pfister, 1998).

"Anger is a natural and automatic response to pain of one form or another (physical or emotional). Anger can occur when people don't feel well, feel rejected, feel threatened, or experience some loss. The type of pain does not matter; the important thing is that the pain experienced is unpleasant. Anger is a strong emotion (Busch, 2009) and never occurs in isolation but rather is necessarily preceded by feelings of pain, it is often characterized as a "second hand emotion”(Mills, 2005). A study has discussed that anger can be a helpful medium to get in touch with one's personal needs, thoughts and feelings (Lerner, \& Lerner, 1985). Harburg, Blakelock, \&Roeper (1979) reported that it is, in fact, possible to handle anger in a healthy way. Researchers have attempted to study two extreme modes of anger- "Anger In" and “Anger Out”. Previous research has proved that health benefits and anger are invariably linked, and that an individual -with high levels of anger -that confides in a family member, friend, acquaintance, or just a supportive listener show notably higher and healthier health status (Thomas, 2003). Sport players are required to be stress-less in order to attain their intended goal, and therefore study of anger in sport players becomes a vital part of research. An investigative team (Haynes, Levine, Scotch, Feinleib, \&Kannel, 1978), along with modes of anger, also studied the concept of 'Anger Discussion' which involves discussion of anger with a trustable person. Anger discussion has a positive impact on health (Thomas and Williams, 1991). "Anger discussion is positively (also) correlated with a stronger sense of self-efficacy and optimism” (Ausbrooks, Thomas, \& Williams, 1995).

Suppression of anger tends to damage relationships, and individuals that suppress their emotion of anger (often females) have been linked to conditions like hypertension, coronary heart disease and cancer (Spielberger, Crane, Kearns, Pellegrin, \& Rickman, 1991). On the contrary, those individuals who are highly expressive with respect to their emotion of anger need to learn the skill of being assertive and need to understand that assertiveness is relatively a healthier and much preferable choice as compared to violence, yelling or howling (incham). "Ineffective ways of expressing anger include: blaming, venting, misdirecting one’s anger toward a neutral thirdparty, silent submissions, and ineffective fighting” (Lerner \& Lerner, 1985). An individual who is an over-expresser of anger is blended to be a more anxious person and tends to feel rejected 


\section{Anger, Emotional Expressivity and Psychological Well-Being in Sports Players}

when his/her partner desires more time and space. Conflicting to that very situation, and underexpresser of anger yearns to attain distance and space when under stress, and may also completely cut-off from the particular relationship if felt threatened by its intensity (Lerner\& Lerner, 1985). Discussion of anger is healthy (Dobbs, Sloan, \& Karpinski, 2007) and nondiscussers are associated with emotional problems, irritability and annoyance (Hochschild, 1979).

Emotional expressiveness has been defined as "The outward display of emotion, regardless of valence (positive or negative) or channel (facial, vocal, or gestural). "Emotional expressivity is the tendency to express emotions through non-verbal actions, such as: tone of voice, posture, and facial expression” (Kring, Smith, \& Neal, 1994). Emotional expressivity, therefore, can be defined in simple terms, such as "the expression of emotions through non-verbal actions" (Kring, Smith \& Neal, 1994). "It appears that the consistent gender differences in the emotion stereotype literature are based on beliefs about the expression of emotion more than they are on beliefs about the emotional experience" (Huston-Comeaux \& Kelly, 2002). This is why the researcher also aims to study both -boys and girls engaged in Instrumental Aggression Sports and Hostile Aggression Sports. Emotional expressivity is a very crucial part of our everyday lives and of our social relationships on which it has a strong influence (Campos, Mumme, Kermoian \& Campos 1994). Researchers have suggested that individuals, in order to maintain healthy and effective communication, should express all emotions ranging from positive to negative, efficiently (Sloan \& Marx, 2004). Effective communication in a team of sport players is necessary for better performance, and hence emotional expressivity in sport players is another very crucial factor of the study.

Research has shown that emotional expressivity has been studied in various psychological fields and is, thus, of great importance. Emotional expressivity shows a major influence on interpersonal interaction (Lavee \& Ben-Ari, 2004). Positive emotions encourage a person to explore for himself and experience new things (Fredrickson, 1998). Contempt and disgust have similar qualities and are just as unacceptable, whereas sadness and fear are seen as relatively less powerful and less of a threat to relationships, and therefore are comparatively more acceptable in collectivistic cultures than in individualistic cultures (Timmers, Fischer \& Manstead, 1998). Thus, there are clear and distinctive differences in how people express their emotions. "There are considerable data to suggest that when individuals actively inhibit emotional expression, they show measurable immunological changes consistent with poorer health outcomes" (Petrie, Booth, \& Davison, 1995). Psychotherapists have drawn the conclusion that emotional expressivity, or the maintenance of the client's expression of emotion, strongly impacts the client's physical, but more importantly and particularly his/her psychological well-being (Leising, Müller, \& Hahn, 2007). 


\section{Anger, Emotional Expressivity and Psychological Well-Being in Sports Players}

"Psychological well-being is the combination of feeling good and functioning effectively" (Huppert, 2009). Psychological well-being has been defined as "a complex, multi-faceted construct that has continued to elude researchers” (Headey \& Wearing, 1989). Ryff's model attempted to understand aspects that constitute well-being: Autonomy; Environmental Mastery; Positive Relationships with others; Purpose in Life; Realization of Potential and Self-Acceptance (Ryff, 1989). It was also believed by researchers that well-being stems from individualistic perception of the world and its situations (Emerson, 1985). The well-being of individual sport players is primary for their focus on the desired goal, and therefore the study of psychological well-being in sport players engaged in Instrumental Aggression Sports and Hostile Aggression Sports becomes beneficial for the understanding of difference and to find out the significance of well-being in sport players. Another definition that came about was "Well-being is more than just happiness, well-being means developing as a person and making a contribution to the community” (Shah, \& Marks, 2004).

Psychological well-being is also related to anger (Diong, \& Bishop, 1999). While in different situations, some individuals tended to express positive emotions like happiness, there were found instances when individuals also expressed the negative emotions such as frustration, anxiety and anger which proved to have a negative impact on their lives (Ben-Zur, 2003). Expression of the emotion anger occurs in possibly three ways: anger-out, anger-in and anger control. Anger control calms individuals helping them cope with stress that individuals challengingly try to cope with every time (Avşaroğlu \& Üre, 2007).

Individuals try to aim at attaining and preserving their psychological well-being by coping with stress and practicing anger control and taking to honest expression of positive emotions instead of the negative ones (Mayer et al., 2004). Athletes in sports attempt to harm an opponent because they usually believe that injuring will increase their chances of victory. Previous research has also brought to focus the several factors that might promote violence in player aggression. Not only do the players alone take to aggression, but the spectators or common fans tend to become aggressive while supporting their preferred teams as well (Wann, 2006). Therefore, it becomes all the more important to study aggression and psychological well-being in sport players in order to understand if hostility in sports generates any natural hostility in the nature of human beings, and this is what the researcher takes keen interest in, in her study.

\section{Objectives}

1) To determine whether there is a role of types of sports (instrumental aggression sports and hostile aggression sports) and gender (boys and girls) on anger (5 dimensions viz. anger arousal, range of anger-eliciting situations, hostile outlook, anger-out, anger-in), emotional expressivity ( 3 dimensions viz. negative emotion facet, positive emotion facet, impulse strength) and psychological well-being (6 dimensions viz. autonomy, environmental mastery, personal growth, positive relations, purpose in life, self-acceptance). 


\section{Anger, Emotional Expressivity and Psychological Well-Being in Sports Players}

2) To study whether there is any relationship between anger, emotional expressivity and psychological well-being in boys and girls engaged in instrumental aggression sports and those engaged in hostile aggression sports

\section{METHOD}

\section{Research Design}

The present study adopts a between-groups design to determine whether there are any gender differences between sport players engaged in instrumental aggression and those engaged in hostile aggression with respect to anger and its 5 dimensions (viz., anger arousal, range of angereliciting situations, hostile outlook, anger-out, and anger-in), emotional expressivity and its 3 dimensions (viz., negative emotion facet, positive emotion facet, impulse strength) and psychological well-being and its 6 dimensions (viz., autonomy, environmental mastery, personal growth, positive relations, purpose in life, self-acceptance). This study also adopts a correlational design to determine whether there is a relationship between, anger, emotional expressivity and psychological well-being and their dimensions among sports players engaged in instrumental aggression sports (Basketball and Hockey) and hostile aggression sports(martial arts - karate and judo).

\section{Sample}

A non-probability purposive sampling technique was used to collect data from 160 sports players, among whom 80 (40 boys and 40 girls) were engaged in instrumental aggression sports and 80 (40 boys and 40 girls) were engaged in hostile aggression sports. Sports Players between the age of 18-24 years, engaged in their respective sport for at least 3 years were included in this study.

\section{Instruments}

Four questionnaires were used in this research. They were:

\section{- Information Schedule}

Participants were asked to provide details regarding their age, gender, educational qualification, employment status, residence, physical and psychological health status, type of sports, and the like in the Information Schedule.

\section{- $\quad$ Multidimensional Anger Inventory(MAI)}

The Multidimensional Anger Inventory (Siegel, 1986)was designed to assess the emotion of anger. Siegel (1986) discovered that there was a significant relationship between anger and coronary heart disease, on the basis of which she formulated five dimensions, namely, anger arousal, range of anger-eliciting situations, hostile outlook, anger out and anger in.

The Multidimensional Anger Inventory consists of 30 items, the $30^{\text {th }}$ item branching out to 9 subquestions. The Inventory is rated on a 5-point Likert-type scale whose responses range from 


\section{Anger, Emotional Expressivity and Psychological Well-Being in Sports Players}

'Completely True' to 'Completely False'. Psychometric analysis of the MAI substantiates that it possess the test-retest reliability $(r=0.75)$ and high internal consistency ( $a l p h a=0.84$ and 0.89$)$ for the two samples of male and female intermediate and undergraduate students.

\section{- $\quad$ Berkeley Expressivity Questionnaire}

The Berkeley Expressivity Questionnaire was developed by Gross\& John in 1998. According to Gross (1998), "Emotional regulation is defined and distinguished from coping, mood regulation, defense, and affect regulation.” The Berkeley Expressivity Questionnaire, was developed to assess three facets of emotional expressivity which include negative emotion facet, positive emotion facet, and impulse strength. Negative Emotion Facet (Negative emotion facet) represents the degree to which negative emotional response tendencies are expressed behaviourally; Positive Emotion Facet (Positive emotion facet) represents the degree to which positive emotional response tendencies are expressed behaviourally; and Impulse Strength is the measurement of the general strength of emotion response tendencies.

This questionnaire constitutes a 16-item scale designed to measure the emotional expressivity of an individual. The responses range on a 7-point Likert-type scale from 1 being 'Strongly Disagree' to 7 conveying 'Strongly Agree'. Gross and John (1995) reported test-retest reliabilities of $r=0.86$ (total scale), $r=0.78$ (negative emotion facet), $r=0.71$ (positive emotion facet), and $r=0.82$ (impulse strength). They also reported and internal consistency ranging from 0.82 to 0.86 . The scale or questionnaire shows great validity - impressive convergent relations with peer rated expressivity $(r=0.53)$ as well as with emotion-expressive behavior.

\section{- $\quad$ Psychological Well-Being Scale}

Ryff's Psychological Well-beinf Scale (Ryff\& Keyes, 1995) is an efficient scale that can aid colleges and universities in understanding the six dimensions that this scale possesses, namely self-acceptance, positive relations with others, autonomy, environmental mastery, purpose of life, and personal growth. The Psychological Well-Being Scale is a 42 item scale that is rated on a 6point Likert-type scale with responses ranging from 'Strongly Disagree' to 'Strongly Agree'. A high score per dimension indicates positive qualities of the individual under that particular dimension, and contrary to that a negative score per dimension is indicative of negative qualities of the individual under that particular dimension. The Psychological Well-Being Scale produces a test-retest reliability (ranging between $r=0.81$ and $r=0.88$ ). It also shows high internal consistency (ranging between 0.86 and 0.93 ).

\section{Procedure}

After selecting the measures, a few arrangements were made for data collection. The Informed Consent Form, information schedule and the questionnaires were prepared and organized. The authorities of various colleges and sports clubs were approached for permission to collect data from sports players.The authorities of colleges and sports clubs that gave permission for data 
collection were contacted. The researcher visited the colleges and sports clubs on the scheduled dates. The students were approached cordially and were made aware that their participation in the study was purely voluntary and that they could choose to be anonymous. They were also informed and assured that confidentiality would be maintained throughout. Students who agreed to participate in the study were requested to sign the Informed Consent Form. Next, the information schedule was administered. Thereafter, the participants who met the criteria of the study were given instructions for the questionnaires (namely, Multidimensional Anger Inventory, Berkeley's Expressivity Scale and Psychological well-being scale) and they were requested to complete the same. No fixed time limit was conditioned to any of the questionnaires. However, the participants were asked to complete filling the questionnaires in the approximate time period of 50 minutes.

\section{RESULTS}

Table 1- Shows the mean, standard deviations and F-value with dimensions of Anger, Emotional Expressivity and Psychological Well-Being as the Dependent Variables and type of sports (Instrumental Aggression Sports and Hostile Aggression Sports) and gender as Independent variables $(n=80)$.

\begin{tabular}{|c|c|c|c|c|c|c|c|}
\hline & \multicolumn{3}{|c|}{ Type of Spouts } & \multicolumn{3}{|c|}{ Gender } & \multirow[b]{2}{*}{$\begin{array}{l}\text { Type of } \\
\text { Sports } \\
\text { Gender }\end{array}$} \\
\hline & $\begin{array}{c}\text { Instrument- } \\
\text { al Agg- } \\
\text { Sports } \\
\end{array}$ & $\begin{array}{c}\text { Hostie } \\
\text { Agg } \\
\text { Sports }\end{array}$ & & Boys & Giils & & \\
\hline Variables & $\begin{array}{c}\text { Mean } \\
\text { (SD) }\end{array}$ & $\begin{array}{c}\text { Mean } \\
\text { (SD) }\end{array}$ & $\mathbf{F}$ & $\begin{array}{c}\text { Mean } \\
\text { (SD) }\end{array}$ & $\begin{array}{c}\text { Mean } \\
\text { (SD) }\end{array}$ & $\mathbf{F}$ & $\mathbf{F}$ \\
\hline Anger Arunsal & $\begin{array}{l}34.66 \\
(7.70)\end{array}$ & $\begin{array}{l}34.05 \\
(8.06)\end{array}$ & 126 & $\begin{array}{l}33.04 \\
(8.75)\end{array}$ & $\begin{array}{l}36.68 \\
(6.72)\end{array}$ & $455^{*}$ & 0.01 \\
\hline Anger Fring Slmations & $\begin{array}{l}29.44 \\
(6.12)\end{array}$ & $\begin{array}{l}29.74 \\
(531)\end{array}$ & $\mathbf{0 . 1 1}$ & $\begin{array}{l}30.04 \\
(5.86)\end{array}$ & $\begin{array}{l}29.14 \\
(5.55)\end{array}$ & 098 & 0.09 \\
\hline Hostie Oribok & $\begin{array}{l}3631 \\
(655)\end{array}$ & $\begin{array}{l}38.19 \\
(727)\end{array}$ & 292 & $\begin{array}{l}36.74 \\
(725)\end{array}$ & $\begin{array}{l}37.76 \\
(6.67)\end{array}$ & 0.87 & 021 \\
\hline Anger $\mathrm{h}$ & $\begin{array}{l}18.14 \\
(3.83)\end{array}$ & $\begin{array}{r}1858 \\
(3.78)\end{array}$ & 0.53 & $\begin{array}{l}18.25 \\
(421)\end{array}$ & $\begin{array}{l}18.46 \\
(3.36)\end{array}$ & 0_12 & 095 \\
\hline Anger Out & $\begin{array}{l}1238 \\
(2.14)\end{array}$ & $\begin{array}{l}12.70 \\
(2.43)\end{array}$ & 0.8 & $\begin{array}{l}1255 \\
(232)\end{array}$ & $\begin{array}{l}1253 \\
(227)\end{array}$ & 0.01 & 2.03 \\
\hline Negrive Fmotion Facet & $\begin{array}{c}291 \\
(0.60)\end{array}$ & $\begin{array}{c}3.11 \\
(0.95)\end{array}$ & 254 & $\begin{array}{c}3.02 \\
(3.65)\end{array}$ & $\begin{array}{c}3.01 \\
(093)\end{array}$ & $\mathbf{0}$ & 0.23 \\
\hline Posive Fmotion Facet & $\begin{array}{c}294 \\
(093)\end{array}$ & $\begin{array}{c}291 \\
(0.84)\end{array}$ & 0.106 & $\begin{array}{c}2.84 \\
(0.93)\end{array}$ & $\begin{array}{c}3.01 \\
(0.70)\end{array}$ & 1.67 & 155 \\
\hline Impolse Strength & $\begin{array}{c}3.04 \\
(0.63)\end{array}$ & $\begin{array}{c}3.04 \\
(0.60)\end{array}$ & $\mathbf{0}$ & $\begin{array}{c}3.00 \\
(0.61)\end{array}$ & $\begin{array}{c}3.09 \\
(0.61)\end{array}$ & 0.88 & 0.66 \\
\hline Antunnmy & $\begin{array}{l}26.24 \\
(5.72)\end{array}$ & $\begin{array}{l}2629 \\
(532)\end{array}$ & $\mathbf{0}$ & $\begin{array}{l}26.24 \\
(5.59)\end{array}$ & $\begin{array}{l}26.29 \\
(5.47)\end{array}$ & $\mathbf{0}$ & 197 \\
\hline Fivionmental Mastery & $\begin{array}{l}26.01 \\
(5.03)\end{array}$ & $\begin{array}{l}26.28 \\
(5.08)\end{array}$ & 0.11 & $\begin{array}{l}26.50 \\
(5.13)\end{array}$ & $\begin{array}{l}25.79 \\
(495)\end{array}$ & 0.81 & 3.64 \\
\hline Personal Growth & $\begin{array}{l}29.84 \\
(5.05)\end{array}$ & $\begin{array}{l}29.49 \\
(493)\end{array}$ & 02 & $\begin{array}{l}29.79 \\
(530)\end{array}$ & $\begin{array}{l}2954 \\
(4-66)\end{array}$ & 0.1 & 152 \\
\hline Positive Relations & $\begin{array}{l}32.68 \\
(527)\end{array}$ & $\begin{array}{l}3321 \\
(7.00)\end{array}$ & 03 & $\begin{array}{l}32.73 \\
(7.03)\end{array}$ & $\begin{array}{l}33.16 \\
(5.23)\end{array}$ & 02 & 0.09 \\
\hline Pupose In Iffe & $\begin{array}{l}26.43 \\
(4.82)\end{array}$ & $\begin{array}{l}2525 \\
(433)\end{array}$ & 278 & $\begin{array}{l}26.03 \\
(4.52)\end{array}$ & $\begin{array}{l}25.65 \\
(4.43)\end{array}$ & 029 & 036 \\
\hline Self Acceptance & $\begin{array}{l}29.14 \\
(538)\end{array}$ & $\begin{array}{l}28.46 \\
(5.02)\end{array}$ & 0.67 & $\begin{array}{l}28.94 \\
(5.45)\end{array}$ & $\begin{array}{l}28.66 \\
(497)\end{array}$ & 0.11 & 2.13 \\
\hline \multicolumn{8}{|l|}{ *0<0.05 } \\
\hline \multicolumn{8}{|l|}{$\neq p<0.01$} \\
\hline $\mathbf{d}=\mathbf{1}$ & & & & & & & \\
\hline
\end{tabular}


Table 1 indicated that there is a significant difference between boys and girls with respect to anger arousal $(\mathrm{F}=4.55, \mathrm{p}<0.05)$. In other words, girls $(\mathrm{M}=36.68)$ tend to show higher anger arousal with increased physiological activity than boys $(\mathrm{M}=33.04)$.

Table 2- Shows the correlation between the dimensions of Anger, Emotional Expressivity, and Psychological Well Being with respect to Instrumental Aggression Sports [N=80].

\begin{tabular}{|c|c|c|c|c|c|c|c|c|c|c|c|c|c|}
\hline & $\begin{array}{c}\text { Anger } \\
\text { Arcusal }\end{array}$ & $\begin{array}{l}\text { Anger } \\
\text { Friting } \\
\text { Stmations }\end{array}$ & $\begin{array}{l}\text { Hostive } \\
\text { Otilock }\end{array}$ & $\begin{array}{l}\text { Anger } \\
\text { Ont }\end{array}$ & Anger In & $\begin{array}{c}\text { Negative } \\
\text { Emotion } \\
\text { Facet }\end{array}$ & $\begin{array}{c}\text { Positive } \\
\text { Fmotion } \\
\text { Facet }\end{array}$ & $\begin{array}{l}\text { Impulse } \\
\text { Strength }\end{array}$ & Antmonny & $\begin{array}{l}\text { Kimiconment } \\
\text { al Mastrery }\end{array}$ & $\begin{array}{l}\text { Personal } \\
\text { Growth }\end{array}$ & $\begin{array}{l}\text { Positive } \\
\text { Retainens }\end{array}$ & $\begin{array}{c}\text { Pupose } \\
\text { In Iffe }\end{array}$ \\
\hline $\begin{array}{c}\text { Negative } \\
\text { Gmation } \\
\text { Facet }\end{array}$ & $-455^{* *}$ & $295^{* *}$ & $527^{* *}$ & .005 & $-446^{* *}$ & & & & & & & & \\
\hline $\begin{array}{c}\text { Postive } \\
\text { Fmotion } \\
\text { Facet }\end{array}$ & $-766^{* *}$ & $233^{*}$ & $372^{* *}$ & .146 & $599^{* *}$ & $322^{* * *}$ & & & & & & & \\
\hline $\begin{array}{l}\text { Imprilse } \\
\text { Strength }\end{array}$ & $578^{* *}$ & 123 & $286^{*}$ & $315^{* *}$ & $-492^{* * *}$ & 168 & $572^{* *}$ & & & & & & \\
\hline Antonomy & -.048 & .121 & -.037 & .031 & -081 & .013 & .113 & -012 & & & & & \\
\hline $\begin{array}{c}\text { Finvicunmental } \\
\text { Mastery }\end{array}$ & $-286^{* *}$ & -146 & $-234^{*}$ & .025 & .000 & -.101 & -097 & -012 & $-429^{* *}$ & & & & \\
\hline $\begin{array}{l}\text { Personal } \\
\text { Gruwth }\end{array}$ & $-226^{*}$ & .054 & -217 & -134 & -087 & -150 & -029 & .070 & $-404^{* *}$ & $-481^{* *}$ & & & \\
\hline $\begin{array}{l}\text { Positive } \\
\text { Relations }\end{array}$ & $-419^{* * *}$ & -.010 & $-319^{* *}$ & -160 & -197 & $-259^{*}$ & $-224^{*}$ & -208 & $304^{* *}$ & $398^{* *}$ & $684^{* *}$ & & \\
\hline $\begin{array}{c}\text { Pupose In } \\
\text { Iffe }\end{array}$ & -069 & 205 & .043 & -.032 & -.063 & .048 & -.008 & -.063 & $310^{* *}$ & $255^{*}$ & $-435^{* *}$ & $537^{* *}$ & \\
\hline $\begin{array}{c}\text { Sel- } \\
\text { Acceptrance }\end{array}$ & $-224^{*}$ & .124 & -.054 & -197 & -099 & -001 & -.062 & -.008 & $507^{* *}$ & $379^{* *}$ & $370^{* *}$ & $-440^{* *}$ & $236^{*}$ \\
\hline$* 0<0.05$ & & & & & & & & & & & & & \\
\hline${ }_{0}^{*}<0,01$ & & & & & & & & & & & & & \\
\hline
\end{tabular}

Table 2 shows that, anger arousal is positively correlated with negative emotion facet $(r=0.455$, $\mathrm{p}<0.01$ ), positive emotion facet $(\mathrm{r}=0.766, \mathrm{p}<0.01)$, and impulse strength $(\mathrm{r}=0.578, \mathrm{p}<0.01)$. In other words, more the anger arousal in a sports player, more the negative emotion facet, positive emotion facet, and impulse strength of the player. Anger arousal is also negatively correlated with, environmental mastery $(r=-0.286, \mathrm{p}<0.01)$, personal growth $(\mathrm{r}=-0.226,<0.05)$, positive relations ( $r=-0.419, \mathrm{p}<0.01)$, and self-acceptance $(\mathrm{r}=-0.224, \mathrm{p}<0.05)$. In other words, more the personal growth, environmental mastery, positive relations, and self-acceptance in a sports player, less is the anger arousal.

As is also evident from the same table, range of anger-eliciting situations is positively correlated with negative emotion facet $(r=0.295, \mathrm{p}<0.01)$ and positive emotion facet $(r=0.233, p<0.05)$. In 


\section{Anger, Emotional Expressivity and Psychological Well-Being in Sports Players}

other words, more the negative emotion facet and positive emotion facet in a sports player, more is the anger arousal of the player.

Additionally, Table 2 reveals that hostile outlook is positively correlated with negative emotion facet $(\mathrm{r}=0.527, \mathrm{p}<0.01)$, positive emotion facet $(4=0.372, \mathrm{p}<0.01)$, and impulse strength $(\mathrm{r}$ $=0.286, \mathrm{p}<0.05$ ). In other words, more the negative emotion facet, positive emotion facet, and impulse strength in a sports player, more is the hostile outlook of the player. Hostile outlook is also negatively correlated with environmental mastery $(r=-0.234, \mathrm{p}<0.05)$ and positive relations $(r=-0.319, \mathrm{p}<0.01)$. In other words more the hostile outlook of a sport player, lesser their environmental mastery and positive relations.

Moreover, Table 2 discloses that anger out is positively correlated with impulse strength $(r=315$, $\mathrm{p}<0.01$ ). In other words more the impulse strength of a sports player, more is the anger out of the player.

Furthermore, Table 2 illustrates that anger in is positively correlated with negative emotion facet $(r=0.446, p<0.05)$, positive emotion facet $(r=0.599, p<0.01)$, and impulse strength $(r=0.492$, $\mathrm{p}<0.01)$. In other words, more the anger in of a sports player, more is the negative emotion facet, positive emotion facet and impulse strength of the player.

Lastly, Table 2 shows negative emotion facet is negatively correlated with positive relations $(\mathrm{r}=$ $-0.259, \mathrm{p}<0.05)$, as is positive emotion facet negatively correlated with positive relations $(\mathrm{r}=$ $0.224, \mathrm{p}<0.05$ ). In other words more the negative emotion facet and positive emotion facet of a sports player, lesser is the positive relations of the player. 
Table 3- Shows the correlation between the dimensions of Anger, Emotional Expressivity, and Psychological Well Being with respect to Hostile Aggression Sports [N $=80]$.

\begin{tabular}{|c|c|c|c|c|c|c|c|c|c|c|c|c|c|}
\hline & $\begin{array}{l}\text { Anger } \\
\text { Arousal }\end{array}$ & $\begin{array}{l}\text { Anger } \\
\text { Friting } \\
\text { Sinations }\end{array}$ & $\begin{array}{l}\text { Hostile } \\
\text { Outhok }\end{array}$ & $\begin{array}{l}\text { Anger } \\
\text { Otit }\end{array}$ & Anger $\mathrm{In}$ & $\begin{array}{c}\text { Negdive } \\
\text { Fimntion } \\
\text { Facet }\end{array}$ & $\begin{array}{c}\text { Postive } \\
\text { Fmotion } \\
\text { Facet }\end{array}$ & $\begin{array}{l}\text { Imprudse } \\
\text { Strengeth }\end{array}$ & Antronmmy & $\begin{array}{l}\text { Finvicunment } \\
\text { al Mastery }\end{array}$ & $\begin{array}{l}\text { Personal } \\
\text { Gruwth }\end{array}$ & $\begin{array}{l}\text { Postive } \\
\text { Retations }\end{array}$ & $\begin{array}{l}\text { Pupose } \\
\text { In Ifife }\end{array}$ \\
\hline $\begin{array}{c}\text { Negative } \\
\text { Fmotion } \\
\text { Facet }\end{array}$ & $301^{* *}$ & -.014 & $-692^{* *}$ & -.003 & $240^{*}$ & & & & & & & & \\
\hline $\begin{array}{c}\text { Postive } \\
\text { Fmotion } \\
\text { Facet }\end{array}$ & $.742^{* *}$ & $273^{*}$ & $295^{* *}$ & .062 & $-445^{* *}$ & 214 & & & & & & & \\
\hline $\begin{array}{l}\text { Impulse } \\
\text { Strength }\end{array}$ & $565^{* *}$ & .096 & $347^{* *}$ & .153 & $555^{* *}$ & $260^{*}$ & $397^{* *}$ & & & & & & \\
\hline Antunnmy & .075 & -046 & -.097 & -193 & -008 & -035 & 062 & 104 & & & & & \\
\hline $\begin{array}{c}\text { Emvicumental } \\
\text { Mastery }\end{array}$ & -.178 & -109 & -126 & .007 & -061 & -.048 & -.055 & -.087 & $348^{* *}$ & & & & \\
\hline $\begin{array}{l}\text { Personal } \\
\text { Growith }\end{array}$ & $-315^{* *}$ & -169 & $-277^{*}$ & -.029 & -187 & $-237^{*}$ & $-278^{*}$ & -100 & $261^{*}$ & $371^{* *}$ & & & \\
\hline $\begin{array}{l}\text { Positive } \\
\text { Retations }\end{array}$ & -.095 & .133 & -.053 & .041 & -.040 & -150 & .027 & .057 & 200 & $382^{* *}$ & $-493^{* *}$ & & \\
\hline $\begin{array}{c}\text { Pupose In } \\
\text { Iffe }\end{array}$ & $-248^{*}$ & 183 & -069 & .156 & 010 & $-338^{* *}$ & $-260^{*}$ & -127 & 146 & .110 & .145 & 129 & \\
\hline $\begin{array}{c}\text { Self- } \\
\text { Acceptance }\end{array}$ & -.059 & -.151 & .040 & -.193 & 132 & 081 & -.052 & .025 & $548^{* *}$ & $368^{* *}$ & $332^{* *}$ & $232^{*}$ & .114 \\
\hline $\mathbf{p}<0.05$ & & & & & & & & & & & & & \\
\hline$* x_{0}^{*}<0.01$ & & & & & & & & & & & & & \\
\hline
\end{tabular}

Table 3 reveals that anger arousal is positively correlated with negative emotion facet $(\mathrm{r}=0.301$, $\mathrm{p}<0.01$ ), positive emotion facet ( $\mathrm{r}=0.743, \mathrm{p}<0.01$ ), and impulse strength $(\mathrm{r}=0.565, \mathrm{p}<0.01$ ). In other words, more the anger arousal of a sports player more is the negative emotion facet, positive emotion facet and impulse strength. Anger arousal is also negatively correlated with personal growth $(\mathrm{r}=-0.315, \mathrm{p}<0.01)$ and purpose in life $(\mathrm{r}=-0.248, \mathrm{p}<0.01)$. In other words, more the anger arousal in a sports player less is the personal growth and purpose in life of the player.

Table 3 also reveals that range of anger-eliciting situations is positively correlated with positive emotion facet $(r=0.273, p<0.05)$. In other words, more the range of anger-eliciting situations in a sports player more is the positive emotion facet of the player.

Additionally, Table 3shows hostile outlook is positively correlated with negative emotion facet ( $\mathrm{r}$ $=0.692, \mathrm{p}<0.01)$, positive emotion facet $(\mathrm{r}=0.295, \mathrm{p}<0.01)$, and impulse strength $(\mathrm{r}=0.347$, $\mathrm{p}<0.01)$. In other words, more the hostile outlook in a sports player, more is the negative emotion facet, positive emotion facet, and impulse strength of the player. Hostile outlook is also negatively correlated with personal growth $(\mathrm{r}=0.277, \mathrm{p}<0.05)$. In other words, more the personal growth of a sports player, lesser is their hostile outlook.

(C) The International Journal of Indian Psychology, ISSN 2348-5396 (e)| ISSN: 2349-3429 (p) | 21 


\section{Anger, Emotional Expressivity and Psychological Well-Being in Sports Players}

Moreover, Table 3 explains that anger in is positively correlated with negative emotion facet ( $\mathrm{r}$ $=0.240, \mathrm{p}<0.05)$, positive emotion facet $(\mathrm{r}=0.445, \mathrm{p}<0.01)$, and impulse strength $(\mathrm{r}=0.555$, $\mathrm{p}<0.01)$. In other words, more the anger in of a sports player, more is the negative emotion facet, positive emotion facet and impulse strength.

Furthermore, Table 3 discloses that negative emotion facet is negatively correlated with personal growth $(r=-0.237, p<0.05)$ and purpose in life $(r=-0.338, p<0.05)$. In other words, more the negative emotion facet in a sports player less is the personal growth and purpose in life of the player.

Lastly, Table 3 illustrates that positive emotion facet is negatively correlated with personal growth $(r=-0.258, p<0.05)$ and purpose in life $(r=-0.260, p<0.01)$. In other words, more the positive emotion facet in a sports player less is the personal growth and purpose in life of the player.

\section{DISCUSSION}

"Instrumental" aggression is different from "hostile" aggression (Averill, 1983). Anger control reflects the degree to which an individual regulates his or her own anger expression (Spielberger et al. 1991). Anger control and jealousy, associated with aggression has been linked to personality or relationship characteristics. Echoing these findings, a study by Tafrate, Kassinoveand Dundin(2002), found that $40 \%$ of a community sample of 93 people reported positive long-term effects of angry episodes, compared with 36\% that reported neutral and $25 \%$ that reported negative long-term outcomes.

Emotions have a significant influence on the initiation, facilitation and maintenance of social relationships (Campos, Mumme, Kermoian \& Campos 1994). It was found that emotional expressivity is positively related to judgements of liking, and that this effect is independent of physical attractiveness and appears to have equal or close to equal explanatory power in predicting rating of interpersonal liking (Sabatelli\& Rubin, 1986).

Ryff and Singer (1991) stated that convergence of similar features of positive psychological functioning constitutes the core dimensions of psychological well-being. Kumar et al.,(2006)observes that conceptions of well-being are integrally related to how one views the nature of man and what perspective is valued. The concept of "psychological well-being" acquired more importance in the field of Psychology over the last decade and in recent years psychological well-being is the focus of intense research attention (Diener, Diener \& Diener 1995). Conflicting relations were said to suppress the association between positive and negative affect of psychological well-being, thereby creating an illusion that the components are independent (Diener, 2000). 


\section{Anger, Emotional Expressivity and Psychological Well-Being in Sports Players}

The present study shows a significant difference between boys and girls with respect to the dimension of anger arousal. Girls and boys do not differ in their experience of anger but also the belief that girls are more likely to express, positively, their anger than boys, while boys are more hostile towards school than girls (Ghanizadeh, 2008). Boys, according to studies, were more likely than girls to use physical expression of their anger (Maccoby, \& Jacklin, 1980). Buss (1989) reported that women were found to have greater anger than men, following condescending remarks, inconsiderate, neglecting or rejecting behaviour, alcohol abuse, and their partner's emotional constriction. Thus, the hypothesis of the present study was supported.

The present study indicates that anger arousal is significantly correlated with negative emotion facet, positive emotion facet, and impulse strength and negatively with environmental mastery, personal growth, positive relations, and self-acceptance; Anger eliciting situations is positively and significantly correlated with negative emotion facet and positive emotion facet; Hostile outlook is significantly and positively correlated with negative emotion facet, positive emotion facet, and impulse strength and negatively with environmental mastery, positive relations and personal growth; Anger out and anger in is positively and significantly in correlation with impulse strength; Negative emotion facet is negatively correlated with positive relations, personal growth, and purpose in life, as is positive emotion facet negatively and significantly correlated with positive relations, personal growth, and purpose in life -all as per the present study.

Researchers have hypothesized that a tendency to express anger may be related to the development of externalizing problems, and a tendency to express sadness may be one marker for later internalizing problems (Chaplin, Cole \& Zahn-Waxler, 2005). A study (Diong \& Bishop,1999)examined the role of anger expression in the experience of stress, coping with stress and psychological and physical well-being and concluded that higher levels of anger were associated with higher levels of stress and simultaneously lower use of active coping -active coping was in turn positively related to psychological well-being. The same study additionally reported higher levels of anger expression showing a direct negative relationship with psychological well-being as did higher levels of stress -the only significant predictor of physical well-being was reported stress, with higher levels of stress related to lower levels of physical well-being (Diong \& Bishop, 1999). Some studies reported a link between emotional expressivity and stress which was as strong as the link between stress and anger. These studies reported that people might be very inexpressive because they have a high threshold for distress elicitation or because they tend to inhibit their expression, therefore highlighting positive expression of emotion as vital (Kennedy-Moore \& Watson, 2001). This therefore, also provides support to the hypotheses of the present study.

A study reported that negative emotionality and the discrete negative emotions were significant predictors of neuroticism, whereas positive emotionality was inversely related to 


\section{Anger, Emotional Expressivity and Psychological Well-Being in Sports Players}

neuroticism(Izard, Libero, Putnam, \& Haynes, (1993). Studies also reported that the quality of family relationships (i.e., degree to which family members are encouraged to express feelings and problems) played a small, yet significant role in predicting career planning attitudes of adolescents, however, those particular adolescents reported freedom from excessive guilt, resentment and anger (Hargrove, Inman \& Crane, 2005). Also, as per some studies, concerning emotional activation, their research has shown that people who express a lot because they have a low threshold for the elicitation of distress -for example, a research centring negative affectivity (NA), which includes a disposition to experience unpleasant or obnoxious emotional states and reports high negative affectivity individuals having a propensity to feel a wide variety of negative moods, including anxiety, frustration, sadness, irritability, and anger, even in the absence of obvious stressors (Watson \& Clark, 1984). Research on anger expression also pin points the benefits of combining cognitive and emotional processing (Kennedy-Moore,\& Watson, 2001).

As per some studies, a relation between shame-proneness, consistently, with anger arousal, suspiciousness, resentment, irritability, a tendency to blame others for negative events, and indirect expressions of hostility, was found. Proneness to guilt, or inability to accept one's own self (self-acceptance), was inversely related to externalization of blame and some indices of anger, hostility, and resentment (Tangney, Wagner, Fletcher, \& Gramzow, 1992). This, thus, further supports the hypotheses of the present study.

According to self-determination theory (Ryan \& Deci, 2000), the term 'autonomy' refers to the "striving to realize one's authentic self, as reflected in one's basic needs and self-chosen values, interests and goals". SDT also depicted that many 'controlling behaviours', such as 'imposing deadlines', 'surveillance', and 'giving directives' undermine intrinsic motivation (Deci, Ryan, \& Williams, 1996). Lazarus (1991) proposed that threats against the one's own self are likely to evoke anger, as well as anxiety and that when the threat is "perceived as an unjust assault" then it interferes with one's trials to realize specific personal goals and, in turn, is likely to arouse anger. This, conclusively, supports the hypotheses of the present study.

The present study does not concern itself with professional sports players who have played for more than 4 years, or other sport activities, and therefore future researchers could take more professional sports players into account as well other different sport activities that could also be considered. This research brings to light the toxic effects of anger and how we can learn to process emotions to augment effective functioning and psychological well-being. The present study can aid sports psychologists to help sports persons work on their anger management, expression of emotions and psychological well-being and also to, more specifically, help the understanding of psyche of those engaged in instrumental or hostile aggression sports. 


\section{Acknowledgments}

The author appreciates all those who participated in the study and helped to facilitate the research process.

\section{Conflict of Interests}

The author declared no conflict of interests.

\section{REFERENCES}

Averill, J. R. (1983). Studies on anger and aggression: Implications for theories of emotion. American psychologist, 38(11), 1145.

Ausbrooks, E. P., Thomas, S. P., \& Williams, R. L. (1995).Relationships among self-efficacy, optimism, trait anger, and anger expression. Health Values: The Journal of Health Behavior, Education \& Promotion.

Avşaroğlu, S., \&Üre, Ö. (2007). The study of styles of coping with stress, decision-making and self-esteem of university students on decision-making in terms of self-esteem and some variables. Selçuk University J.Soc. Sci. Institute, 18, 85-100.

Ben-Zur, H. (2003). Happy adolescents: The link between subjective well-being, internal resources, and parental factors. Journal of Youth and Adolescence, 32(2), 67-79.

Busch, F. N. (2009). Anger and depression. Advances in Psychiatric Treatment, 15(4), 271-278.

Buss, D. M. (1989). Sex differences in human mate preferences: Evolutionary hypotheses tested in 37 cultures. Behavioral and brain sciences, 12(01), 1-14.

Campos, J. J., Mumme, D. L., Kermoian, R., \& Campos, R. G. (1994). A functionalist perspective on the nature of emotion. Monographs of the society for research in child development, 59(2-3), 284-303.

Chaplin, T. M., Cole, P. M., \& Zahn-Waxler, C. (2005). Parental socialization of emotion expression: gender differences and relations to child adjustment. Emotion, 5(1), 80.

Coulomb, G., \&Pfister, R. (1998). Agressive Behaviors in Soccer as a Function of Competition Level and Time: A Field Study. Journal of Sport Behavior, 21(2), 222.

Deci, E. L., \& Ryan, R. M. (2000). The" what" and" why" of goal pursuits: Human needs and the self-determination of behavior. Psychological inquiry, 11(4), 227-268.

Deci, E. L., Ryan, R. M., \& Williams, G. C. (1996). Need satisfaction and the self-regulation of learning. Learning and individual differences, 8(3), 165-183.

Diener, E. (2000). Subjective well-being: The science of happiness and a proposal for a national index. American psychologist, 55(1), 34.

Diener, E., Diener, M., \&Diener, C. (1995).Factors predicting the subjective well-being of nations. Journal of personality and social psychology, 69(5), 851.

Diong, S. M., \& Bishop, G. D. (1999).Anger expression, coping styles, and well-being. Journal of Health Psychology, 4(1), 81-96.

Dobbs, J. L., Sloan, D. M., \& Karpinski, A. (2007).A psychometric investigation of two selfreport measures of emotional expressivity. Personality and Individual Differences, 43(4), 693-702.

Fredrickson, B. L. (1998). Cultivated emotions: Parental socialization of positive emotions and self-conscious emotions. Psychological Inquiry,9(4), 279-281.

Ghanizadeh, A. (2008). Distribution of symptoms of attention deficit-hyperactivity disorder in schoolchildren of Shiraz, south of Iran. Arch Iran Med, 11(6), 618-624. 


\section{Anger, Emotional Expressivity and Psychological Well-Being in Sports Players}

Harburg, E., Blakelock Jr, E. H., \& Roeper, P. J. (1979). Resentful and reflective coping with arbitrary authority and blood pressure: Detroit. Psychosomatic Medicine, 41(3), 189-202.

Hargrove, B. K., Inman, A. G., \& Crane, R. L. (2005). Family interaction patterns, career planning attitudes, and vocational identity of high school adolescents. Journal of Career Development, 31(4), 263-278.

Haynes, S. G., Levine, S. O. L., Scotch, N., Feinleib, M., \& Kannel, W. B. (1978).The relationship of psychosocial factors to coronary heart disease in the Framingham Study I. Methods and risk factors. American journal of Epidemiology, 107(5), 362-383.

Headey, B., \& Wearing, A. (1989). Personality, life events, and subjective well-being: toward a dynamic equilibrium model. Journal of Personality and Social psychology, 57(4), 731.

Hochschild, A. R. (1979). Emotion work, feeling rules, and social structure. American journal of sociology, 551-575.

Huppert, F. A. (2009). Psychological Well-being: Evidence Regarding its Causes and Consequences†. Applied Psychology: Health and Well-Being,1(2), 137-164.

Hutson-Comeaux, Sarah L., and Janice R. Kelly. "Gender stereotypes of emotional reactions: How we judge an emotion as valid." Sex Roles 47.1-2 (2002): 1-10.

Izard, Libero, Putman, \& Haynes. (1993). Stability of emotion experiences and their relations to traits of personality. Journal of Personality and Social Psychology, 1993;64:847-860.

Kennedy-Moore, E., \& Watson, J. C. (2001). Expressing emotion: Myths, realities, and therapeutic strategies. Guilford Press.

Kring, A. M., Smith, D. A., \& Neale, J. M. (1994). Individual differences in dispositional expressiveness: development and validation of the Emotional Expressivity Scale. Journal of personality and social psychology, 66(5), 934.

Kumar, A., Roberts, D., Wood, K. E., Light, B., Parrillo, J. E., Sharma, S., \& Gurka, D. (2006). Duration of hypotension before initiation of effective antimicrobial therapy is the critical determinant of survival in human septic shock. Critical care medicine, 34(6), 1589-1596.

Lavee, Y., \& Ben-Ari, A. (2004). Emotional expressiveness and neuroticism: Do they predict marital quality?. Journal of Family Psychology, 18(4), 620.

Lazarus, R. S. (1991). Progress on a cognitive-motivational-relational theory of emotion. American psychologist, 46(8), 819.

Leising, D., Müller, J., \& Hahn, C. (2007).An adjective list for assessing emotional expressivity in psychotherapy research. Clinical Psychology \& Psychotherapy, 14(5), 377-385.

Lerner, H. G., \& Lerner, H. G. (1985). The dance of anger: A woman's guide to changing the patterns of intimate relationships.

Maccoby, E. E., \& Jacklin, C. N. (1980). Sex differences in aggression: A rejoinder and reprise. Child development, 964-980.

Mayer, J. D., Salovey, P., Caruso, D. R., \& Sitarenios, G. (2001).Emotional intelligence as a standard intelligence.

Petrie, K. J., Booth, R. J., \& Davison, K. P. (1995). Repression, disclosure, and immune function: Recent findings and methodological issues.

Ryff, C. (1989). Happiness is everything, or is it? Explorations on the meaning of psychological well-being. Journal of Personality and Social Psychology, 57, 1069-1081.

Ryff, C., \& Keyes, C. (1995). The structure of psychological well-being revisited. Journal of Personality and Social Psychology, 69, 719-727.

Ryff, C. D., \& Singer, B. (1996). Psychological well-being: Meaning, measurement, and implications for psychotherapy research. Psychotherapy and psychosomatics, 65(1), 14-23. 


\section{Anger, Emotional Expressivity and Psychological Well-Being in Sports Players}

Sabatelli, R. M., \& Rubin, M. (1986).Nonverbal expressiveness and physical attractiveness as mediators of interpersonal perceptions. Journal of Nonverbal Behavior, 10(2), 120-133.

Shah, H., \& Marks, N. (2004). A well-being manifesto for a flourishing society. New Economics Foundation.

Silva, J. E., \& Larsen, P. R. (1983).Adrenergic activation of triiodothyronine production in brown adipose tissue.

Sloan, D. M., \& Marx, B. P. (2004).Taking pen to hand: Evaluating theories underlying the written disclosure paradigm. Clinical Psychology: Science and Practice, 11(2), 121-137.

Spielberger, C., Crane, R. S., Kearns, W. D., Pellegrin, K. L., Rickman, R. L., \& Johnson, E. H. (1991). Anger and anxiety in essential hypertension. Stress and emotion, 14, 266-283.

Tangney, J. P., Wagner, P., Fletcher, C., \&Gramzow, R. (1992). Shamed into anger? The relation of shame and guilt to anger and self-reported aggression. Journal of personality and social psychology, 62(4), 669.

Thomas, S. P. (2003). Men's anger: A phenomenological exploration of its meaning in a middleclass sample of American men. Psychology of Men \& Masculinity, 4(2), 163.

Thomas, S. P., \& Williams, R. L. (1991).Perceived stress, trait anger, modes of anger expression and health status of college men and women. Nursing Research, 40(5), 303-307

Timmers, M., Fischer, A. H., \& Manstead, A. S. (1998).Gender differences in motives for regulating emotions. Personality and Social Psychology Bulletin, 24(9), 974-985.

Wann, D.L. (2006). Examining the potential causal relationship between sport team identification and psychological wellbeing. Journal of Sport Behaviour, 29, 79-95.

Watson, D., \& Clark, L. A. (1984). Negative affectivity: the disposition to experience aversive emotional states. Psychological bulletin, 96(3), 465.

https://www.mentalhelp.net/articles/psychology-of-anger/

How to cite this article: N Sanyal, T Fernandes, N Vizarath (2016), Anger, Emotional Expressivity and Psychological Well-Being in Sports Players, International Journal of Indian Psychology, Volume 3, Issue 4, No. 65, ISSN 2348-5396 (e), ISSN: 2349-3429 (p), DIP: 18.01.136/20160304, ISBN: 978-1-365-34680-4 